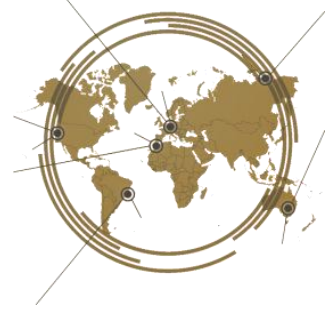

\title{
English and international students' adjustment in Indonesian higher education: A teacher's perspective
}

\author{
Hamamah*, Yulia Hapsari \\ Faculty of Cultural Studies, Universitas Brawijaya, Indonesia
}

International students at higher education in Indonesia encounter an extent of situations amid their adaptations in academic life. These experiences contribute to their satisfaction. As handful of studies within Indonesian context were conducted to identify the international students' difficulties in adapting to academic life, teacher's point of view toward the issue is barely available. This study centers at a teacher's experience in dealing with the international students. Highlight is given to language barrier that is not only encountered by the international students but also the teacher. A narrative inquiry was employed involving an academic leader who is also a teacher knowledgeable in internationalization agenda in higher education in Indonesia. Results of the study reveals that the academic adaptation of international students, with the focus of language barrier, was compounded by the absence of roadmap of internationalization policy in national and organizational levels, less-ideal classroom setting, and not effective interaction within classroom with the diversity of people involved. In attempt to help international students with their academic adjustment, it is suggested that the policy on the proficiency of English language should be regulated to be mastered by students and teachers in international program, the classroom setting should be rearranged to support the academic adaptation of international students, and the interaction between students and teachers in the class needs to be supported by counterpart for the international students. In addition to that, more exposure on English should be provided within international program.

Keywords: International students, academic adjustment, language barrier, English proficiency

OPEN ACCESS

ISSN 25033492 (online) ${ }^{*}$ Correspondence:

Hamamah

hamamah@ub.ac.id

Received: 4th January 2021 Accepted: 1st September 2021 Published: 4th September 2021

Citation:

Hamamah and Hapsari, Y. (2021). English and International Students'

Adjustment in Indonesian Higher Education: A Teacher's Perspective.

\section{INTRODUCTION}

International students' enthusiasm to pursue their study in Indonesian universities seems to keep growing. It can be learned from information shared by the Ministry of Research Technology and Higher Education Republic of Indonesia that informs that 6.967 License of Learning had been issued by the Directorate of Institutional Development of Higher Education during 2016. Consequently, higher education institutions in Indonesia have to be ready in accommodating the international students during their life as university students in Indonesia. The institutions readiness is a part of realization of internationalization programs in Indonesian higher education that is assessed by the Ministry of Research Technology and Higher Education Republic of Indonesia. 
However, the increasing number of the international students also incurs more challenges, among which are faced by teachers teaching the international students. The fact that the international students are learning in the same class as the domestic students demands the teacher to keep all members of the class on the same page. This seems not an easy job when students do not share the same language proficiency, let alone when they hardly speak the same language.

Ellis and van Aart (2013) asserted that academic, culture, and university services are the major considerations in studying abroad. The academic concerns professors, courses delivered in foreign language, and instructional methods employed. The culture, on the other hand, includes the location of the city in which the university resides, and its atmosphere. Then, the university services involve help desk, counseling, accommodation and assimilation activities.

Learning from what happened in Australia regarding the international students' academic adaptation process, it can be concluded that the students generally come across ranges of problems during their adjustment into a new educational system. Wang and Xiao (2014) argued that in the beginning, the students seemed to have a hard time adjusting to Australian academic environment as it is essentially distinct from their previous experience. Further, for higher degree research students, socio-cultural adjustment imposes considerable effects on the students' academic success as well as their psychological well-being.

Language proficiency is identified as a main issues faced by international students taking higher degree research in Australia. Son and Park (2014) pointed out that inadequacy in English proficiency persistently becomes a main hindrance for the international students in adapting to their life in Australia. For the international students whose native language is not English have often demonstrated to face difficulties in academic reading, writing and oral presentations.

Responding to the international students' challenges in adjusting to their new academic life, a lot of host universities have provided supports for language and academic skills to improve the students' academic success. A study by Ward and Masgoret (2004) showed a positive relationship between host language skills and international students' personal life satisfaction in New Zealand. However, Mak (2009) study in demonstrated that there is no relationship between the two variables when the study was conducted to Chinese students studying in Australia.

Non-English speaking students also experience this obstacle. Ibragimova \& Tarasova (2018) studied students from non-Russian speaking countries who continue their study in Russia. In this case, the medium of teaching is Russian, yet some international students have low Russian language performance. The results showed that low host language skills affected the students' academic and adjustment. Meanwhile, in Indonesia, a study by Lutfiana et al. (2020) about Thai undergraduate students who studied in Indonesia. The Thai students are not fluent in Indonesian and English, yet the medium of teaching is in English.
The low proficiency in English leads to the students' low academic performance.

The international students who have low English proficiency find it difficult to follow the learning process when English is the medium of teaching (Mei, 2017). The difficulties are primarily in oral, academic writing, especially in grammar and terminology connected to the study (Cennetkușu, 2017; Ibragimova \& Tarasova, 2018). The difficulties faced by the international students were their capability in academic writing. The students are able to write many sentences in their mother tongue language, but when transferring it into a foreign language, it does not make sense. Since having less vocabulary in the academic writing genre, the different grammatical features, and having no academic writing course (Cennetkușu, 2017). This is in line with Hamamah and Nurhayani (2017) study about the academic writing of Libyan students who studied in Indonesia. The teaching medium is entirely in English, while the students are not fluent in both Indonesian and English. The findings show that the writing achievement of the Libyan students was not satisfying. They were many errors grammatically and rhetorically. It is also found that English learning teaching is hard to happen if the L1 of the teacher and students are not the same and they do not understand each other's L1.

Another hardship for the university to conduct courses using foreign language as the instructional media lies in the struggle of providing ample resources and support to help the international program. From the researchers' observation it is revealed that the international programs' host is still facing difficulties in providing English exposure towards international students. Individual student are somewhat reluctant to improve their lack of proficiency in English because they do not recognize it as the cause of difficulties in their studies (Ballard and Clanchy, 1991). Additionally, Ma (2020), from her research on Chinese students' who continue to study abroad, found that the students prefer to stay in the same communities rather than stay with domestic friends or international friends. This led to low progression of their English skill.

To overcome that, many universities find some solutions, including offering English language classes as the mode of concurrent support to international students. For example, Ali et al. (2020) state some suggestions to overcome students' stress about the language barrier, they proposed to lengthen the duration of their language classes up until one year long. Not only that, but they also proposed the lecturers and staff to take the English class as progress is needed not only on the students' side. Additionally, Cennetkușu (2017) provide another kind of support that is feedback from the lecture or people outside the department to the students. The feedback would be very helpful for the international students. Other suggestions that can be provided to international students to improve their English are to refer to the dictionary and published journal article to improve the vocabulary and to gain experience in academic writing through a publication, which will provide editor's feedback. 
The latter can help them to improve their writing academic ability.

It is also essential to make the student realize their English skills and exceed their self-efficacy. One of the strategies proposed by Ma (2020) on how to make the students learn and break the language barrier is they need to be forced to not stay in their communities. As Edward and Ran (2006) state, the experiences of International students in their host countries usually involve features such as cultural, psychological, social, and academic adjustments.

Adjustment is a dynamic and interactive process that takes place between the person and the environment and is directed towards the achievement of the fit between the two (Anderson, 1994). Thus, Academic adjustment is a fit for a learner in the academic environment. Many researchers consider academic adjustment a complex process that impacts all university students (Barker, et al., 1991). The primary reason is that the culture of education differs from country to country. For example, universities in advanced countries pay more attention to class participation. The educational approach in these countries looks unfamiliar to international students who are habituated to expect more guidance and support from teachers.

The previous research mostly talks about international students' points of view on the language barrier they are facing. However, similar research from Indonesia as the background is hardy found. Also, there is not much research which discuss teacher's point of view. To fill this gap, this study elaborates teacher's experience about the language barrier that is not only encountered by the international students but also the teacher in Indonesian higher education. This study also provides some suggestions on how to break the language barrier from teacher's perspectives.

\section{METHODS}

This study is a narrative research as it centers on the story of a teacher teaching international students in Indonesian higher education. In narrative research the researcher focuses on studying a single person through the story of his/her experience with a main objective to find out the meaning of the story (Ary et.al, 2010; Creswell, 2012). Data was gathered through spoken or written stories about experiences told by the individual. Then, the researcher and the individual will collaboratively undergo sequencing and re-storying process to understand the meaning of the experience being told (Ary et al., 2010; Creswell, 2012). In order to conduct the study, a series of research procedure was conducted. It starts from identifying a phenomenon that addresses a problem, selecting an individual from whom the phenomenon can be learnt, collecting the stories from the individual that reflect personal experience, transcribing and re-transcribing the stories, analyzing and sequencing the story, and finally looking for themes (Ary et al., 2010).

Initially, this study was triggered by a phenomenon of the rapid increase of international students' academic mobility in Indonesian higher education. Prior to Covid-19 outbreak, strong encouragement from Indonesian government about internationalization agenda was given. As a consequence, more and more international students were coming to Indonesian higher education. This phenomenon leads to questioning challenges especially the ones related to language barriers faced by both international students and their teachers in adjusting to a new academic life. This topic is highlighted as there are many international students who come from various countries with various native languages, in which English is a foreign language. As the students and teachers will heavily rely on English as a medium of instruction during the study, adequate English proficiency to cope with academic discussion is of paramount importance. Unfortunately, it seems that not all of the international students joining the academic mobility program are equipped with it.

The success of academic adjustment of the international students requires active involvement of academic leaders and teachers knowledgeable in internationalization agenda in higher education. Therefore, this research selected a Vice Dean of Academic Affairs Faculty of Cultural Studies Universitas Brawijaya as the individual from whom international students' experience in academic adjustment in higher education can be learnt. Aside from being a vice dean, the research participant is also a teacher of international students studying at the institution. She has been actively teaching and dealing with the international students studying at the institution through various programs, starting from non-degree program, bachelor program, to master's degree program. She also has considerable experiences related to international students that led her to be granted DIES Training Course "Management of Internationalization Indonesia" by DAAD Germany.

Stories from this prominent teacher as the research participant were collected from interviews conducted during close interactions in a period of time. Vast arrays of information related to language barrier that is not only encountered by the international students but also the teacher in Indonesian higher education as well as strategies on how to break the barrier was gathered as the data of this study. The results of the interviews were then transcribed and analyzed to look for elements of setting and existing condition at a certain time to be further sequenced to find out the plot and meaning underlying the story. From this process, some conclusions were made, and some lessons were learnt.

\section{RESULTS AND DISCUSSION}

From the analysis of the teacher's story, the researchers identified three main themes concerning the challenges in the academic adaptation of international students with the highlight of language barriers: policy level, classroom setting, and interaction. 


\section{Policy Level}

The research participant highlighted the policy matter as one of the causes of the language barrier problem that might hurdle the academic adaptation of international students. The process of internationalization of higher education in Indonesian context is progressing slowly because there is no clear grand-design of the plan that mapped the pathways and connected all elements concerning the internationalization, including the major policies and regulations (Kyrychenko, 2018; Sutrisno, 2019). Many universities, then, operate the internationalization with immature planning. Because of that, one of the main problems that emerge along the way of internationalization which also happens a lot in other nonEnglish speaking countries, is the language barrier, that is the lack of English language competence (Abduh et al., 2018; Kyrychenko, 2018). The example of the lack of policy regulating the internationalization in her university is that her university does not yet set standard of English proficiency level as entry requirement for international students.

'There is no standard for the English proficiency... for international students' entry requirement in the uni. That's why, there are many international students from the non-English speaking countries with lack of English communication skills enrolled here. I know that we all are struggling with English and I know that they [international students]are required to learn Bahasa Indonesia, but when there is no prerequisite of certain English proficiency, it will make the situation in class becomes very difficult for the students and the teachers.'

The research participant shared a concern that the absence of the English proficiency requirements at the enrollment is possibly for responding to the government's regulation that internationalization of universities are measured, among others, by the number of international students enrolled.

'Maybe, the reason is also to attract more international students to study here. We have to promote our uni so that we can have more international students to fulfill the contract with governments' in which, among other, university are measured based on certain criteria including the number of international students enrolled.'

The research participant reported that as a teacher and an academic leader she needs feedback from the international students. She then conducted a survey to international students from non-English speaking countries who studied in the university. One of the objectives of the survey is to see the effect of the absence of the requirement of English proficiency in enrollment to find out the students' background experience with English.

'The international students who responded to my survey were 23 students from different faculties in the uni. The result of a survey showed that only 2 students who had ever taken IELTS and 2 others had taken TOEFL. While, the rest of the students were acknowledged to have never taken any of the tests. The interesting thing is that most of the international students do not seem to worry about their English proficiency as most of them are confident that their English is good. This situation needs to be changed. The uni must regulate the English language proficiency standard soon.'

The research participant also revealed that the international students also had concerns with lecturers' qualifications. This is in line with the study conducted by Ellis and van Aart (2013), which took Australia as its setting, it was argued that there are three most critical concerns about studying abroad. One of the concerns is the qualification of the professors, lessons in different languages, and methods used.

'...in the beginning of their involvement in the classroom learning, the international students usually ask us [the lecturers] for the information on our academic background. They asked for my academic qualification... well where I studied.. like that. When I told them that I earned my doctorate degree from a well-known university in Australia, they seemed to be satisfied.'

Thus, she informs further that higher education institutions need to consider having a regulation or design concerning the lecturers' qualifications for teaching in international programs.

\section{Classroom Settings}

The research participant addresses that classroom setting with regard to the composition of the people involved ( $\underline{\text { Guo }}$ \& Guo, 2017), and their English proficiency level has also contributed to the academic adjustment of international students. The international program offered in the research participant's university is attended by local students and international students. She explains the students' diversity in the program.

'The international program usually consists of students with different background. Some are international students, and the others are local students. The international students can be from English or nonEnglish speaking countries. Some of the local students have completed previous education within English Medium Instruction (EMI), while others attend educational programs in foreign language other than English or in Bahasa Indonesia.'

She also explains the diversity in the lecturers' part.

'The lecturers also have various backgrounds. Some of them have pursued their master and/or doctoral degree overseas and some others completed their education in Indonesia and never been abroad. So, those who study abroad have experiences with international multicultural context, while those who studied in Indonesian context haven't got this kind of experience.'

These dynamics in classroom setting often cause difficulties for international students in adjusting themselves to the academic interaction in class.

'The differences of students' and teachers' English language proficiency, culture and learning backgrounds cause different hopes and assumption from the class interactions. Often there is understanding between teachers' and students or among students about course 
expectations, all because of the difficulties in understanding each other due to language barrier.'

Unlike Ballard and Clanchy (1991) who argued that students' English proficiency is often the sole cause of the difficulties faced by students, this study reveals that although it is true, the lecturers' inadequate English proficiency also contributes to the difficulties in the students' academic adjustment.

\section{Interaction}

The internationalization of higher education has driven the universities in the non-English speaking countries, including Indonesia, to offer English-medium instruction (EMI) (Byun et al., 2011; He \& Chiang, 2016). The research participant shared her experiences and views of the interaction of the students and teachers in EMI programs in her department. Personally, she is convinced that there is a real challenge in confirming students' understanding about any lesson delivered in English. She explained that her international students wrestled with lessons that are delivered.

'Well, the communication in class is always difficult with students who are coming from non-English speaking countries. But the highest challenge that I experienced was when there were international students in my class who were coming from Libya. Their native language is Arabic, which I don't know,... their English is low and they can only understand very little Bahasa Indonesia. I always needed extra effort to make them understand the material I taught in English. They also struggled very much in understanding the lesson.'

She explained further that the challenge was even escalated for the students and her when dealing with a written assignment. Academic writing is the most demanding task for the international students with a lack of English.

'The writing assignments and thesis are the worst struggle that we had during the pedagogical interaction. Whenever there is written assignment, I always provided one-to-one conference with each of them to discuss in detail about their progress..., but often times was not enough. Therefore, completing assignments on time were considered difficult.'

She also found that the international students' academic adjustment was also hindered by the fact that in classroom interactions, some lecturers and staff cannot speak fluent English. This makes the students could not understand the content of the lecture clearly.

'The international students expressed that language was the most difficult thing they faced to adjust with the academic life. Even worse, some lecturers use Bahasa Indonesia and sometimes Javanese as the language of instruction in the class so that all explanations and presentations were given in Bahasa Indonesia.'

She stated further that these facts in classroom interaction between international students lacking of English and teachers with different English proficiencies and different experiences in international academic context might have caused the students to have concerns with the lecturers' qualification and educational background.
This result is in line with Ali et al. (2020) about the needs of English training not only on students but also the professors and the staff.

\section{CONCLUSION}

This study shows that the academic adjustments of international students, especially those from the non-English speaking countries, into Indonesian academic context are often difficult because of the language barrier. The academic adaptation with the focus of language barrier was compounded by the absence of roadmap of internationalization policy in national and organizational levels, less-ideal classroom setting, and not effective interaction within the classroom with the diversity of people involved.

The language barrier, however, also comes from the lecturers who have inadequate English proficiency. This situation imposes more challenges to the international students adjusting to the academic life. Consequently, to help international students with their academic adjustment, it is suggested that the policy on the proficiency of English language should be regulated to be mastered by students and teachers in the international program, the classroom setting should be rearranged to support the academic adaptation of international students, and the interaction between students and teachers in the class needs to be supported by a counterpart for the international students. Apart from that, more exposure on English should be provided within the international program.

\section{ACKNOWLEDGEMENTS}

The authors would like to thank the Faculty of Cultural Studies Universitas Brawijaya for granting the access for this study to be conducted. Invaluable thanks also go to Amanda and Hilda for all the helps and supports in the completion of this article. Finally, the authors would like to thank the anonymous reviewer for the valuable comments and feedback.

\section{REFERENCES}

Abduh, A., Rosmaladewi, R., \& Basri, M. (2018). Internationalization Awareness and Commitment of Indonesian Higher Education. New Educational Review, 51(1), 162-171. doi: 10.15804/tner.2017.50.4.13

Ali, S., Hery Yoenanto, N., \& Nurdibyanandaru, D. (2020). Language Barrier is the cause of Stress among International Students of Universitas Airlangga. 242256.

Anderson, L. . (1994). A new look at an old construct: Cross -cultural adaptation. International Journal of Intercultural Relations, 18, 293-328. 
Ary, D., Cheser Jacobs, L., Razavieh, A., \& Sorensen, C. K. (2010). Introduction to Research in Education (8th ed.). Wadsworth, Cengage Learning.

Ballard, B. and Clanchy, J. (1991). Teaching Students from Overseas: a brief guide for lecturers and supervisors. Longman Cheshire.

Barker, M., child, C., gallois, C., jones, E. \& callan, V. . (1991). Differences of overseas students in social and academic situations. Australian Journal of Psychology, 43, 79-84.

Byun, K., Chu, H., Kim, M., Park., I., Kim, S., \& Jung, J. (2011). English-medium teaching in Korean higher education: policy debates and reality. High Educ, 62, 431-449. https://doi.org/10.1007/s10734-010-9397-4

Cennetkuşu, N. (2017). Journal of Language and Linguistic Studies International students "challenges in academic writing: A case study from a. Journal of Language and Linguistic Studies. 13(2), 309-323.

Creswell, J. W. (2012). Educational Research: Planning, Conducting, and Evaluating Quantitative and Qualitative Research (4th ed.). Pearson.

Edward, V. \& Ran, A. (2006). Meeting the needs of Chinese students in British higher education.

Ellis, H., \& van Aart, J. (n.d.). Key influencers of international student satisfaction in Europe.

Guo, Y., \& Guo. (2017). Internationalization of Canadian higher education: discrepancies between policies and international student experiences. Studies in Higher Education, 42(5), 851-868. https://doi.org/10.1080/03075079.2017.1293874

Hamamah, \& Nurhayani, I. (2017). International Conference on Higher Education Enhancing Competitiveness in Asia. Contrastive Rhetoric on English Text Written by Libyan Students Studying in Universitas Brawijaya, 157-172. https://fib.ub.ac.id/wpcontent/uploads/2020/02/PROCEEDING-ICHE2017.pdf

He, J., \& Chiang, S. (2016). Challenges to english-medium instruction (EMI) for international students in china: A learners' perspective: English-medium education aims to accommodate international students into chinese universities, but how well is it working? English Today, 32(4), 63-67. https://doi.org/http://dx.doi.org/10.1017/S026607841 6000390

Ibragimova, E. R., \& Tarasova, A. N. (2018). Languagerelated problems of international students of Elabuga Institute of Kazan Federal University. Espacios, $39(2)$.

Kyrychenko, V. (2018). Indonesias' Higher Education: Context, Policy, and Perspective. Asian Journal of Contemporary Education, 2(2), 159-172. https://doi.org/https://doi.org/10.18488/journal.137.2 018.22.159.172

Lutfiana, Suwartono, T., \& Akter, M. (2020). Overseas Students ' Language and Culture Barriers towards Acquiring Academic Progress: A Study of Thai Undergraduate Students. 3(04), 107-114.
Ma, J. (2020). Supporting practices to break chinese international students' language barriers: The first step to facilitate their social adjustment. Journal of International Students, 10(1), 84-105. https://doi.org/10.32674/jis.v10i1.773

Mak, A. S. (2009). Chinese international students' English proficiency, social interactions with locals, and satisfaction of life in Australia. In N. Voudouris \& V. Mrowinski (Eds.). Proceedings of the 44th Australian Psychological Society Annual Conference, 97-102.

Mei, L. (2017). Perceptions of Academic English Language Barriers and Strategies: Interviews with Chinese International Students [University of Washington]. https://digital.lib.washington.edu/researchworks/bitstr eam/handle/1773/38564/Mei_washington_0250O_16 903.pdf? sequence $=1$ \&isAllowed $=y$

Son, J. B., \& Park, S. S. (2014). Academic experiences of international $\mathrm{PhD}$ students in Australian higher education: From an EAP program to a PhD program. International Journal of Pedagogies and Learning, 9, 26-37.

Sutrisno, A. (2019). Internationalization of Indonesian Higher Education: Recent Initiatives and their Problems. International Higher Education, 97, 1213.

https://doi.org/https://doi.org/10.6017/ihe.2019.97.10 941

Wang, Y., \& Xiao, F. (2014). East Asian international students and psychological well-being: A systematic review. Journal of International Students, 4, 301313.

Ward, C., \& Masgoret, A. M. (2004). The experiences of international students in New Zealand. Report on the results of the national survey. The Ministry of Education.

Conflict of Interest Statement: The authors declare that the research was conducted in the absence of any commercial or financial relationships that could be construed as a potential conflict of interest.

Copyright (C) 2021 Hamamah and Yulia Hapsari. This is an open-access article distributed under the terms of the Creative Commons Attribution License (CC $B Y)$. The use, distribution or reproduction in other forums is permitted, provided the original author(s) and the copyright owner(s) are credited and that the original publication in this journal is cited, in accordance with accepted academic prac- tice. No use, distribution or reproduction is permitted which does not comply with these terms. 